\title{
10 Distinction between categories of customers or orders
}

So far we have discussed one or two methods of forecasting the expected demand. We wish to emphasize that in a given concrete case, all the customers, orders or articles need not necessarily be treated in exactly the same way.

If a number of articles in a range have different sales channels, this may be reason enough to employ a different method of forecasting. A range of components required for the assembly of a number of end products may include some which are so universal in scope that the demand can be forecast as effectively, and very much more cheaply, say, by the single smoothing method as by the explosion method. If a large, but irregular, part of the demand for a given article is furnished by a small group of customers, it may well be worth while to try to obtain further information from these customers concerning their share of the demand, whilst forecasting the remainder of the demand according to an extrapolation method.

In a discussion which took place some years ago, Goudriaan [Go 2] had the following to say on this point: "The extreme skew distributions $\dagger$ should be avoided by making a fundamental distinction between stocks to serve a large group of small customers and stocks for a small group of major customers - which is in fact merely the naturally evolved division of labour between wholesale and retail trade'.

Although it may not always appear advisable to keep separate stocks for different purposes, it is sometimes possible to combine different methods of forecasting. For example, there is the situation in which stock components are supplied not only to the assembly belt, but also to the development and service departments. The assembly demand can then be determined by explosion (at any rate in the case of large assemblies planned sufficiently far in advance) and the remainder of the demand (probably: the relatively smaller quantities required) can be estimated by extrapolation methods. In these circumstances it may be advisable from the organizational point of view, to keep a separate 'petty stock' for the minor sources of demand, which is then replenished periodically from the central stock.

$\dagger$ Of size order or of monthly demand figures. 